\title{
BREVE REFLEXIÓN SOBRE LA MODERNIZACIÓN DEL LENGUAJE JURISDICCIONAL ${ }^{1}$
}

\author{
Silvia MARTÍNEZ CANTÓN \\ Magistrada-Juez y Profesora de Derecho Penal \\ Consejo General del Poder Judicial y Universidad Internacional de La Rioja
}

$\mathrm{E}$ 1 lenguaje jurídico se caracteriza por incorporar recursos lingüísticos propios, como son su jerga y el recurso a locuciones arcaizantes y latinismos provenientes, en el civil law ${ }^{2}$, del

Derecho romano. Tales propiedades hacen del mismo un tecnolecto (González Salgado, 2009, 236; Muñoz Machado, 2017: 2). En los últimos años se ha escrito con mayor intensidad sobre el lenguaje que se utiliza en el ámbito jurídico. En el presente artículo se pretenden abordar las propuestas de algunos de los escritos que proponen cambios sobre el lenguaje jurisdiccional y que, fundamentalmente, han sido escritas por lingüistas. En este caso, se examinarán desde una perspectiva más jurídica que lingüística tratando de utilizar múltiples ejemplos que permitan una adecuada comprensión por cualquier lector que no sea ni lingüista ni jurista.

Existe una idea generalizada de que el lenguaje jurídico, y en concreto el jurisdiccional, es críptico para el ciudadano común. Se alega incluso, en virtud de tal inaccesibilidad, que el ciudadano podría no conocer la norma por no entenderla, pese a que, como reza el principio jurídico, la ignorancia de la norma no exime de su cumplimiento. Basta observar por un momento nuestra sociedad para comprobar que a diario se realizan multitud de actos regidos por normas desconociendo incluso el contenido de las mismas. De manera silenciosa, el Derecho lo invade todo. El uso del ascensor o de las escaleras para salir de casa se rige por los estatutos de la comunidad de propietarios y por la Ley de Propiedad Horizontal. La obligación de los vehículos de parar ante el paso de peatones que está frente a nuestra vivienda se rige por la Ley sobre Tráfico, Circulación de Vehículos a Motor y

\footnotetext{
${ }^{1}$ Escribo esta aportación en homenaje y profunda gratitud a José Enrique, maestro a lo largo de toda mi vida en lo personal y en lo profesional y ejemplo a seguir cada día. A través de él, he aprendido, entre muchas otras cosas, a amar la lectura, a cuidar el lenguaje, la forma de expresarme y la claridad en la comunicación de ideas. El resto de mi formación ha consistido en adquirir algunas destrezas y ampliar mi vocabulario, tarea motivadora para quien partía de tan sólida base. De ese vocabulario adquirido posteriormente, entre otras cosas, hablaré en este artículo para mostrarle la pequeña parte de camino que he recorrido sola, sin que sirva para saldar con el homenajeado lo mucho que he recibido. A él, a mi padre, le debo tanto, que no puedo expresarlo en palabras.

${ }^{2}$ El civil law proviene del derecho romano y se materializa en codificar sus leyes. Se opone al common law en que éste proviene del derecho germánico, es parco en leyes y acuden al sistema de precedente en las resoluciones judiciales, que suponen en sí mismas una forma de regulación.
} 
Seguridad Vial. El acto de adquirir el pan a diario es la compra-venta civil. Si devolvemos una prenda que adquirimos pero respecto a la que hemos cambiado de idea, lo hacemos amparados por la Ley General de Defensa de los Consumidores y Usuarios. Cuando reprendemos a los hijos por su mal comportamiento, articulamos el derecho de corrección conforme a los deberes que nos impone el ejercicio de la patria potestad. Y así, sin apenas darnos cuenta, nuestro comportamiento diario discurre pacíficamente por los cauces del Derecho otorgando denominaciones comunes a actos regulados y con denominación técnico-jurídica.

La sociedad utiliza terminología jurídica con habitualidad sin poder aseverar que el término se utilizó de forma exacta, lo cual muchas veces no es así. Se suele escuchar «la paga para mi expareja», en lugar de «la pensión de alimentos a favor mi hijo menor», «denuncia» confundido con «demanda», «acuerdo con el juez» en lugar de «acuerdo judicial», «herencia» para referirse al testamento y viceversa, «carta de finiquito» por «carta de despido» «discapacidad» por «incapacidad» y a la inversa, entre otras muchas. También existe mucha confusión entre los participantes en los procesos, confundiéndose al juez con el fiscal o al fiscal con los abogados. Igualmente, existe terminología que se utiliza con bastante corrección como orden de alejamiento, préstamo, alquiler, bien inmueble u, hoy en día, gestación subrogada. Si bien es probable que tales términos generaran dificultades para ser definidos, el uso en las conversaciones comunes es correcto también desde una perspectiva jurídica, sin poder precisar en muchos casos si es el ámbito jurídico el que adoptó tales palabras del acervo social, o a la inversa. Términos que no se utilizan de forma única en la oratoria jurídica — ejemplo de términos exclusivamente jurídicos son recusación, proveyente, prejuzgar, litisconsorcio, fehaciente, entre otros-, pudieran provenir del uso social, científico o de la continuación de instituciones jurídicas existentes ya en la época romana.

En los primeros textos legislativos ya se aspiraba a la utilización de términos que pudieran ser entendidos por todos, dotándolos de objetividad, para que su significado no pudiera ser tergiversado, tratando de lograr con ello la mayor precisión posible. Ya el Digesto (533: 33. 10. 7. § 2) rezaba que «las palabras no deben interpretarse de acuerdo con las opiniones de cada uno, sino de acuerdo con el uso común» (non enim ex opinionibus singulorum, sed ex communi usu nomina exaudiri debere). La aspiración a la objetividad en la terminología jurídica ha sido siempre una preocupación, tratándose ampliamente la interpretación objetiva y subjetiva. Un ejemplo de ambos tipos de interpretación sería la que se puede realizar en los contratos. Sería una interpretación subjetiva la que se base en la voluntad de los contratantes en el momento de cerrar el acuerdo, y sería una interpretación objetiva la que, por el contrario, se base en la declaración concreta contenida y firmada en el propio contrato aunque ésta finalmente no concuerde con lo que las partes acordaron. El art. 1281 del Código Civil, en estos casos de discordancia, hace prevalecer el sentido del contenido del contrato cuando sus palabras son claras, manteniendo así vigente el aforismo latino in claris non fit interpretatio.

El rigor terminológico al que se aspira con el lenguaje jurídico conlleva también dificultades, ya que una palabra no necesariamente significa lo mismo en una rama u otra del Derecho. El legislador puede decidir dar distintos significados al mismo vocablo en función de la norma. Así, es distinto el 
término «funcionario» utilizado en Derecho administrativo del término «funcionario» utilizado en Derecho penal. El primero se recoge en el artículo 8 de la Ley del Estatuto Básico del Empleado Público de 2015, que delimita el concepto «empleado público», desglosándolo en: funcionarios de carrera e interinos y personal laboral y eventual, siendo la persona funcionario incluso cuando se encuentre de vacaciones; por su parte, el artículo 24.2 de nuestro Código Penal, a los efectos de responsabilidad penal, define como funcionario a «todo el que por disposición inmediata de la Ley o por elección o por nombramiento de autoridad competente participe en el ejercicio de funciones públicas», siendo, por tanto, un concepto mucho más amplio que el de funcionarios de carrera e interinos basándose únicamente en el mero ejercicio de una función pública, pudiendo ejercerla cualquier persona, incluso por designación, no siendo funcionario público a efectos penales quien no se encuentra realizando, en el momento del delito, una función pública, todas ellas figuras diferentes dentro de nuestro ordenamiento jurídico.

Yendo más allá, puede resultar dudosa la trasposición de un término perfectamente claro en derecho español a un texto jurídico de cualquier otro país hispanoparlante, ya que la definición legal que haya podido ofrecer el legislador argentino, chileno, o nicaragüense pudiera diferir de la definición española. Del mismo modo, un único concepto jurídico puede adquirir diversas denominaciones de un país a otro. Se puede indicar, a modo de ejemplo, el término «persona moral», del artículo 25 del Código Civil mexicano, que alberga el mismo concepto que el término «persona jurídica», recogido por nuestro ordenamiento jurídico en el artículo 35 de nuestro Código Civil. De utilizarse en derecho español el término «persona moral» podría surgir confusión sobre si, con la misma, se pretende hacer referencia a las masas patrimoniales u otro tipo de entidades sin personalidad jurídica. Si se conviene, por tanto, en que si el mismo término puede contener diversas acepciones técnicas en virtud del país hispanoparlante, no se puede obviar que la trasposición de términos jurídicos de un idioma a otro puede no ser siempre exacta ya que las instituciones jurídicas varían considerablemente de un sistema jurídico a otro. Por ejemplo, la palabra inglesa duress en derecho penal puede ser traducida por «coacción»o por «situación de estado de necesidad» o por «situación de legítima defensa» en función del contexto.

La aspiración de lograr la mayor comprensibilidad posible en del lenguaje jurídico puede observarse históricamente en fueros y ordenamientos medievales. Así, la Ley II título XXVII del Ordenamiento de Alcalá regula «cómo deben entenderse las palabras de las leyes, fueros e ordenamientos» y La Ley III «por qué palabras se entiende ser dada la justicia». El actual Código Civil, aprobado en 1889 regula, en el art. 3.1., la interpretación de las normas, indicando que deberán interpretarse según el sentido propio de sus palabras, en relación con el contexto, los antecedentes históricos y legislativos y la realidad social del tiempo en que deben ser aplicadas. Desde los años setenta, se han desarrollado por todo el mundo campañas de lenguaje llano (plain lenguaje movement) que han llegado hasta el lenguaje jurisdiccional.

Los últimos intentos más relevantes en España de alcanzar la sencillez en el lenguaje jurisdiccional han sido la Carta de derechos de los ciudadanos ante la administración de justicia de 2002, el impulso por el Plan de transparencia judicial de 2005 de la creación de la Comisión de 
Modernización del Lenguaje Jurídico - por Orden JUS/3126/2003, de 30 de octubre, en el Ministerio de Justicia y por Acuerdo de Consejo de Ministros de 30 de diciembre de 2009-, el Informe emitido por esta en el año 2011 y el Libro de Estilo de la Justicia en este año 2017. En la Carta de derechos mencionada en primer lugar reza: «6. El ciudadano tiene derecho a que en las vistas y comparecencias se utilice un lenguaje que, respetando las exigencias técnicas necesarias, resulte comprensible para los ciudadanos que no sean especialistas en derecho. Los Jueces y Magistrados que dirijan los actos procesales velarán por la salvaguardia de este derecho. 7. El ciudadano tiene derecho a que las sentencias y demás resoluciones judiciales se redacten de tal forma que sean comprensibles por sus destinatarios, empleando una sintaxis y estructura sencillas, sin perjuicio de su rigor técnico». El último libro distingue los textos legales respecto de los de otras disciplinas en virtud de dos notas diferenciadoras: la finalidad por contener mandatos vinculantes dirigidos a personas e instituciones y el alcance de su repercusión institucional, social, económica e individual (Muñoz Machado, 2017: 4). Indica igualmente que no es exclusivamente la terminología lo que hace oscuro el discurso jurídico, sino las técnicas de redacción empleadas.

El mayor problema en las propuestas de modernización del lenguaje surge de los denodados intentos de los lingüistas-no-juristas de suprimir expresiones propias de este ámbito de comunicación bajo la consideración de que las mismas no aportan nada, sino que oscurecen la comunicación con el ciudadano. Las paradojas de objeto y de contenido, esta última especialmente referida a la vaguedad o ambigüedad del lenguaje, hacen que se aconseje evitar determinada terminología (Muñoz Machado, 2017: 101 y ss.). Sin embargo, ¿en qué medida se puede conseguir acercar el discurso jurídico de las resoluciones judiciales cuando se requiere utilizar terminología técnica para dotar de precisión a la resolución evitando así esta vaguedad? Lo cierto es que resulta difícil apreciar la necesidad de tal terminología para quien no se dedica a este tipo de discurso jurídico.

El uso de la jerga jurídica implica el dominio exacto de su vocabulario. El vocabulario jurídico surge de la necesidad de designar determinadas instituciones o figuras que conllevan consecuencias «jurídicas». El uso del mismo dota al discurso jurídico de precisión gracias a la unificación del contenido de dicha terminología a través de las definiciones legales. Como ejemplos de definiciones legales puede citarse el artículo 26 del Código Penal, en donde se define el término «documento» a efectos penales; el artículo 27.2.b), de la Ley de Procedimiento Administrativo, que, en su párrafo segundo, define «digitalización» desde el punto de vista administrativo; el artículo 142 del Código Civil, que define «alimentos»; o el artículo 1 del Código de Comercio, el cual define «comerciantes».

El Libro de Estilo de la Justicia (Muñoz Machado, 2017: 106) hace una breve enumeración de pleonasmos habituales en el lenguaje jurídico cuyo uso se desaconseja y que, de haber sido revisadas tales propuestas por un jurista, quizás no se habrían incluido por ser ejemplos desafortunados. Así, se incluye entre ellos como elemento redundante a desterrar el «testigo presencial» — también denominado «testigo directo»-, al considerarse desde un punto de vista lingüístico que todo testigo lo es de forma presencial. Sin embargo, en el ámbito jurídico, cuando resulta imposible acudir a testigos presenciales, se puede acudir al testimonio de testigos referenciales, es decir, aquellos testigos 
que, si bien no han presenciado el hecho, tienen conocimiento del mismo por lo que les han relatado otras personas y no por haberlo percibido de forma personal y directa. El valor del testimonio prestado por el testigo de referencia es muy inferior al prestado por el testigo presencial. De hecho, la propia Ley de Enjuiciamiento Criminal, en el art. 710, se refiere a los testigos de referencia. La jurisprudencia ha determinado al respecto que su testimonio es subsidiario o complementario a otros medios de prueba. Por el contrario, la declaración prestada por un testigo presencial puede ser suficiente para destruir el principio de presunción de inocencia sin necesidad de pruebas adicionales. Por ese motivo, en una resolución judicial completa y exacta sería recomendable precisar si el testimonio del que el juez realiza su valoración proviene de un testigo presencial o de un testigo de referencia. Lo mismo podría también plantearse de una «participación activa», puesto que, en el ámbito penal se contrapone a la «participación omisiva», o «persona humana» que equivale a «persona física» en contraposición a las personas jurídicas. En definitiva, lo que en el lenguaje común pudiera parecer el uso innecesario de redundancias (carácter explicativo), en el lenguaje jurídico adquiere una función de precisión técnica (carácter especificativo).

A la vista de lo que se acaba de exponer, cobran plena vigencia las palabras de Cazorla Prieto (2007: 75): «por mucho que parte de las circunstancias sociales que prevalecen en la actualidad tiendan a desfigurar el lenguaje jurídico con pretensión última, inconfesada, pero latente, de diluirlo, mezclarlo con el lenguaje común hasta perder todo rasgo identificativo, por mucho que la corriente actual de la sociedad favorezca estos extremos, el lenguaje jurídico para cumplir su misión, debe seguir siendo un lenguaje especial con los andamiajes precisos para sustentar su condición científica. Debo respaldar, sin embargo, la postura que pretende alcanzar una redacción jurídica más cuidada y correcta gramaticalmente, desterrando estructuras gramaticales arcaicas. Un ejemplo sería la utilización habitual de los letrados en los interrogatorios de la coletilla «¿no es más cierto que...?», la cual, basándonos en una comprensión actualizada, parece exigir al testigo una gradación de la certeza en la respuesta a sus preguntas, por cuanto unas son más ciertas que otras.

Con todo lo anterior, no se debe perder de vista que el texto jurisdiccional debe ser comprensible para el destinatario, ya que, de otro modo, se produce una ruptura en la comunicación. Esta claridad en el lenguaje se adquiere mediante frases más cortas y un estilo más directo. Puede así sugerirse la utilización en las sentencias de la primera persona para la expresión de opinión jurídica de quien la dicta, evitándose la autoalusión del juez en tercera persona («este juzgador piensa»). Sin embargo, algunas de las propuestas realizadas buscan simplificar el lenguaje prescindiendo de términos más cultos sin plantearse la capacidad de comprensión que puede tener el lector de la resolución. Por poner un ejemplo concreto, en el informe de la Comisión de Modernización del Lenguaje Jurídico se sugiere la sustitución de la palabra «mendaz» por «falsa» indicando que el mismo es un arcaísmo. La mera consulta del diccionario de la Real Academia de Jurisprudencia permite verificar que el adjetivo «mendaz» no es tratado como término arcaico. Cabe al menos plantearse si, de aparecer tal adjetivo en cualquier otro tipo de texto, por ejemplo, en un periódico, se sugeriría que se dejara de usar. 
En el mismo texto (Comisión de Expertos de Modernización del Lenguaje Jurídico, 2009: 12) se recomienda que «el registro léxico empleado por aquellos [los profesionales del derecho] debe adaptarse siempre al destinatario con el que se relacionan y, en aquellos casos en que estos no sean juristas, evitar las expresiones oscuras y explicar el significado de los términos técnicos». Sin embargo, ninguna de las propuestas indica al juez en qué momento concreto y con fundamento en qué norma debe evaluar la capacidad de comprensión lingüística de las partes para adaptar así el lenguaje que utilice al dictar sentencia. Esto conllevaría que, en caso de encontrarnos ante unos demandantes con buena formación, lo correcto sería utilizar un lenguaje más elevado y, en caso contrario, un lenguaje más común en el que se prescinda del vocabulario técnico. En el caso de encontrarnos ante un procedimiento seguido entre una parte muy versada en el ámbito jurídico frente a otra iletrada, procedería el dictado de dos sentencias en dos niveles distintos de lenguaje. Llevado al extremo, por ejemplo, sería aceptable que el juez de vigilancia penitenciaria adaptara su lenguaje al de la población reclusa.

Tal exigencia de utilización de un lenguaje más llano conlleva también una serie de efectos que no han sido analizados cuando se aplica exclusivamente este deber al juez. En primer lugar, cada juez representa el poder judicial del Estado y conoce que está prestando un servicio público que resuelve controversias. A través de sus resoluciones, el juez no solo pretende resolver conflictos, sino que pretende mostrar una sólida formación jurídica que permita al ciudadano y a los letrados confiar en su conocimiento. No cabe duda de que fundamentar una decisión en la referencia a un artículo de un texto legal cuyo contenido no se copia en la resolución puede resultar confuso para el ciudadano. Tampoco proceder al copiado de dicho texto aseguraría la comprensión para quien no está versado en leyes. Pretender una explicación en cada sentencia del contenido de cada artículo, resultaría tan tedioso que, además de reducir la productividad, haría perder el hilo argumental y contribuiría a la oscuridad del texto. Prescindir por completo de citas legales simplificaría mucho, pero no se correspondería con la respuesta que debe darse en el apartado denominado «fundamentos de derecho» y que se incluye por expresa exigencia de la ley. La utilización por el juez en sus resoluciones de un lenguaje común o coloquial evitando el uso de terminología técnica podría conllevar una degradación de la imagen que ofrece la Justicia al dar las resoluciones una sensación de baja formación por parte de quien juzga. A su vez, conllevaría la pérdida de confianza en el sistema judicial por parte del ciudadano.

En segundo lugar, el juez también piensa que sus decisiones pudieran ser recurridas ante un tribunal superior y que podrían ser posteriormente revocadas y que debe mostrar en largos y variados argumentos con buenos fundamentos jurídicos lo que ha motivado su resolución. Ha sido el propio Tribunal Constitucional el que históricamente ha insistido en realizar sentencias con extensas motivaciones y referencias legales continuas. Tal tendencia al exceso de motivación ha sido limitada en muchos otros ordenamientos, bastando en algunos países europeos con la fijación de hechos probados, la mera cita del artículo aplicado y el sentido de la decisión. Dice Ferreira da Cunha (1998: 838) que «el exceso de palabras conduce, no a la demiurgia, sino a transformar al juez en un aprendiz de brujo». El Tribunal Supremo limitó a veinticinco páginas los recursos de lo contencioso- 
administrativo como mecanismo para poder afrontar su resolución en tiempo y plazo. Del mismo modo, esta tendencia debería trasladarse a las resoluciones judiciales requiriendo al juez resolver con la motivación breve, básica y suficiente sin generar una cantidad innecesaria de oraciones y párrafos que hacen farragosa la sentencia. Al fin y al cabo, la brevedad en la motivación, especialmente si esta es correcta y sencilla, no contradice el art. 120 de la Constitución, es decir, no disminuye las garantías del ciudadano ante la justicia.

En tercer lugar, la utilización de un lenguaje inadecuado a la actividad enjuiciadora conllevaría profundas imprecisiones en las sentencias. Así, por ejemplo, cuando se utiliza el término «ensañamiento» en una resolución penal se hace siempre en el sentido que dictamina el art. 22.5 del Código Penal, evitando siempre la utilización coloquial que, en ocasiones - aunque no siempre-, pudiera coincidir con el término jurídico. Puesto que el ensañamiento jurídicamente es «aumentar deliberadamente el sufrimiento de la víctima», que un cadáver reciba cien puñaladas no es ensañamiento, por cuanto la persona fallecida no sufre dolor. De utilizarse en términos coloquiales e imprecisos en la sentencia, se podría dar lugar a la aplicación de un incremento de pena que no correspondería de haberse tratado el término con rigurosidad.

En cuarto lugar, se reitera continuamente en los textos citados que el lenguaje jurídico es un tecnolecto que, al contrario que otros, debe ser comprensible para el ciudadano sin pararse a analizar que otros tecnolectos son objeto de prueba en el propio acto de juicio. Así, cuando comparece un perito sobre mecánica del automóvil utilizará terminología en parte incluso incomprensible para el juzgador, quien sí tiene la posibilidad de solicitar una nueva explicación. Lo mismo sucede cuando se trata sobre vicios en la construcción donde intervienen arquitectos como peritos, o cuando declara un médico. Toda esta terminología que, en la mayoría de las ocasiones, sirve para fijar los hechos probados se traslada a la sentencia incluso mediante la cita exacta de párrafos de estos expertos. Pretender que sea el juez quien realice una supuesta adaptación de ese lenguaje pericial con el que a él se lo han explicado, para que sea comprensible para las partes resulta, cuanto menos, un objetivo arduo difícil.

En quinto lugar, el juez se erige involuntariamente en protagonista de todo el proceso. El ciudadano presume que toda resolución emanada de un juzgado proviene del juez, aunque también algunas de estas dimanan del Letrado de la Administración de Justicia. Se ha difundido en los medios la existencia de un proceso de digitalización de la justicia, pero el ciudadano ignora su alcance. Así, hace años se implantó en los juzgados la llamada «tramitación guiada» por un programa de gestión procesal. Los objetivos de esta tramitación guiada, no sólo eran agilizar y uniformar la tramitación de los procesos judiciales en todos los territorios, sino utilizar modelos idénticos en todos los juzgados. Así, por ejemplo, las citaciones emitidas por los juzgados de Albacete son idénticas a las citaciones cursadas por los juzgados de Zaragoza y se elaboran de forma automática por estos programas. Estos modelos son elaborados e introducidos en el programa por la Subdirección General de Nuevas Tecnologías del Ministerio de Justicia. El ciudadano sigue percibiendo términos imperativos en las notificaciones que muchas veces no comprende, no cumpliéndose así el requerimiento establecido en la Carta de Derechos del Ciudadano «5. El ciudadano tiene derecho a que las notificaciones, citaciones, 
emplazamientos y requerimientos contengan términos sencillos y comprensibles, evitándose el uso de elementos intimidatorios innecesarios». Sin embargo, el lenguaje de estas notificaciones podría ser mejorado de forma muy sencilla mediante una revisión por el Ministerio de Justicia de las plantillas empleadas. Trasladar esta misión de revisión al juez implicaría perder la uniformidad y la agilidad en la tramitación.

En sexto lugar, se considera constantemente que el ciudadano recibe las resoluciones sin que tenga a su disposición ayuda alguna para interpretarlas. Sin embargo, esto no es cierto. Muchos de los párrafos de las sentencias se dedican a realizar un resumen de lo percibido en sala y un razonamiento sobre lo que pudo haber sucedido hasta fijar lo que se denominan «hechos probados». Estos párrafos suelen ser comprensibles para la media de ciudadanos. Cosa distinta son los argumentos jurídicos que hacen decidir el sentido de la decisión, que por su especialidad no siempre resultan fáciles de comprender. La creencia del ciudadano de que una resolución es linguiísticamente inaccesible hace que este ni se enfrente a la lectura de la misma y decidir por sí mismo qué párrafos en concreto no ha comprendido. El ciudadano tiene a su disposición extensas posibilidades que le permiten acceder al contenido exacto de las notificaciones judiciales. Una de ellas es el procurador. Las resoluciones que emanan de los órganos judiciales no suelen ser notificadas exclusivamente a las partes, sino que se realiza a través de los procuradores y letrados. La figura misma del procurador surge para representar procesalmente a la parte. De hecho, el Procurator en derecho romano era aquella persona de confianza del dominus que llevaba sus asuntos legales y económicos y en quien delegaba para que le representara. Posteriormente debía dar cuenta de sus actos, se presume que de forma comprensible para aquella persona a la que representaba. Hoy en día se puede enmarcar la labor del procurador en la prestación de servicios a su cliente mediante un contrato de mandato del que posteriormente deberá rendir cuentas. Es en este proceso de rendición de cuentas donde debe producirse la «adaptación lingüística»para el cliente, debiendo recibir este una explicación del contenido de la sentencia. Esta labor, en la actualidad, la está cumpliendo el letrado.

Del mismo modo, si el ciudadano acude a la oficina del órgano que le remite la resolución, nunca se le deniega una explicación de la misma, si bien, esta explicación suele conllevar una exigencia de rectificación de la resolución cuando no le es favorable. Tal exigencia no puede ser atendida si no es por los medios que ofrece el derecho, esto es, mediante la presentación de un recurso. Esto provoca que el ciudadano suela regresar decepcionado indicando que la resolución no le ha sido debidamente explicada, confundiendo el acceso al lenguaje de la sentencia con la motivación y fallo de la sentencia. Se omite en el examen de la comunicación de la justicia con el ciudadano la existencia de Servicios de Orientación Jurídica en los juzgados, servicios de carácter gratuito prestados por los Colegios de Abogados y que, igualmente, auxilian al ciudadano en la lectura de escritos judiciales. Por último, en este apartado no puede dejar de citarse el derecho incluido en la Carta de Derechos del Ciudadano ante la justicia: «1. El ciudadano tiene derecho a recibir información general y actualizada sobre el funcionamiento de los juzgados y tribunales y sobre las características y requisitos genéricos de los distintos procedimientos judiciales. Se impulsará la creación y dotación material de Oficinas de 
Atención al Ciudadano, asegurando su implantación en todo el territorio nacional». Este derecho, redactado ya en el año 2002 y que permitiría al ciudadano entender mejor el curso y el contenido de su procedimiento, sigue sin cumplirse por las instituciones, ya que de la mera consulta a la página web del Consejo General del Poder Judicial (http://www.poderjudicial.es/cgpj/es/Servicios/AtencionCiudadana/Oficinas-de-atencion-ciudadana/Directorio-de-oficinas/) se puede advertir que ni siquiera se ofrece información sobre las mismas.

En séptimo lugar, no debería promoverse un lenguaje «más llano», sino una nueva utilización del lenguaje jurídico así como una estructura más definida de las resoluciones. Los operadores jurídicos no son escépticos ante los cambios cuando estos conllevan un beneficio. Más aún, están acostumbrados a adaptarse a los cambios. Sin embargo, ninguno de los proyectos indicados ha conseguido convencer de las bondades de un cambio de lenguaje, sino más bien todo lo contrario. La utilización de arcaísmos, de estructuras complejas, de fórmulas prerredactadas y la asunción como propia de la dicción literal de argumentos de sentencias ajenas —el llamado «copia-pega», indispensable hoy en día debido a la enorme carga de trabajo - no se considera adecuada por la mayoría de los técnicos jurídicos. Tampoco es loable el utilizar modelos de sentencias cuando se trata la misma cuestión jurídica, a través de los cuales no se puede permitir el juzgador no profundizar en el caso concreto, sino abordarlo de manera genérica (Ledesma Ibáñez, 2014: 15) y, con ellos, altamente especializada. Tras todas estas críticas no se atisba una alternativa que permita pulir el lenguaje manteniendo la elegancia y la terminología propia. Así, por ejemplo, se sugiere la eliminación de latinismos (Comisión de Expertos de Modernización del Lenguaje Jurídico, 2011: 12), utilizando en su lugar la misma frase en castellano. Lo habitual hoy en día es utilizar ambas dicciones, una de ellas entre paréntesis. No se percibe qué mejoría comportaría eliminar latinismos. De hecho, su utilización es frecuente porque, a través del mismo, se puede inferir que el principio jurídico aplicado ha sido establecido en siglos anteriores y que su validez es tan irrebatible que ha llegado hasta hoy. Tal frecuencia en su uso se asume en el Libro de Estilo de la Justicia indicando meramente cómo debe incluirse correctamente en el texto (Muñoz Machado, 2017: 211).

Por último, se atribuye al juez la labor de hacer accesible el lenguaje jurídico al ciudadano, ya sea en la llevanza de la sala, ya sea en sus resoluciones. No existen proyectos que pretendan hacer el lenguaje de los escritos literarios más llano y con vocabulario más simple para que puedan ser leídas por todos, pese a que la literatura también debería estar al alcance de todos. De hecho, se presume que las resoluciones permitirán adquirir un mayor nivel cultural a sus lectores. Pleite Guadamillas (2014: 8 ) incluso llega a hablar de que los fallos juegan un papel «normativo y educativo». Se fomenta en la escuela la adquisición de un vocabulario más elevado y la utilización de una sintaxis más compleja de la cual pretende desvestirse posteriormente al juez en aras del beneficio al ciudadano. Pero, como ya se ha dicho, el ciudadano vive inmerso en un mundo jurídico. Hemos visto cómo secuencialmente, con los distintos modelos de enseñanza, se ha polemizado con la introducción en el currículo educativo de asignaturas como «educación para la ciudadanía», la cual podría ser de enorme utilidad si se utilizaran los contenidos de la misma para familiarizar al alumno con el mundo jurídico. Un día ese alumno 
crecerá y necesitará remitir una solicitud administrativa, o registrar su inmueble, repartir una herencia, o negociar una hipoteca. Al ciudadano se le está desproveyendo de armas esenciales en su vida no incluyendo en el currículo una asignatura que le permita adquirir vocabulario jurídico y conocimientos para la consulta de legislación. Resulta incluso poco creíble a estas alturas que una explicación de una resolución para aquella persona que tiene un total desconocimiento del derecho y del sistema jurídico pueda ser satisfactoria, por mucho que trate de adecuarse a su nivel de comprensión. Tampoco se advierte que haya cursos de formación iniciáticos para personas con un nivel de formación más avanzado en otros campos. Por ejemplo, no se ha considerado la posibilidad de que un ingeniero desee adquirir una mínima formación jurídica para su propio desenvolvimiento como persona. La única vía que podrá encontrar es el estudio universitario.

Por todo lo expuesto, estimo que debe producirse una reformulación de las propuestas estilísticas y linguiísticas en el lenguaje jurisdiccional. No se trata únicamente de que el lenguaje jurídico utilizado en los juzgados sea comprensible para el ciudadano, sino también de que el ciudadano tenga una mínima formación jurídica que le permita acceder al lenguaje jurídico. Estas nuevas propuestas deben partir desde las instituciones públicas, tal y como ya se ha hecho, pero implicando a otros sectores que han sido excluidos de este proceso. Alcanzar propuestas realistas y aceptables solo se conseguirá incluyendo en las Comisiones de Modernización a expertos de cada una de las materias jurídicas asî como implicando al Ministerio de Educación.

\section{Bibliografía}

CAzOrla Prieto, L. Ma (2007): El lenguaje jurídico actual. Pamplona, Aranzadi.

COMISIÓN DE EXPERTOS DE MODERNIZACIÓN DEL LENGUAJE JURÍDICO: Informe de 2011.

GonZÁlez SAlgado, J. A. (2009): «El lenguaje jurídico del siglo XXI», THEMIS: Revista de Derecho, 57, pp. 235-245.

MuÑOz MACHADO, S. (dir.). (2017): Libro de estilo de la Justicia. Barcelona, Espasa, Real Academia Española, Consejo General del Poder Judicial.

LEDESMA IBÁÑEZ, Ma del Pilar (2014): «La sentencia como compromiso de reflexión personal y personalizada», Cuadernos Digitales de Formación, 17, pp. 1-21.

Pleite Guadamillas, Fco. (2014): «Acceso a la justicia y relación de los ciudadanos con los tribunales de la jurisdicción contencioso-administrativa», Cuadernos Digitales de Formación, 20, pp. 1-23.

Krueger, P., Mommsen, T. (1870). Digesta Iustiniani Augusti. Berolini: apud Weidmannos, en https//catalog.hathitrust.org/Record/011549567 (última consulta, 7-8-2017). 